Egyptian

Orthodontic Journal

\title{
MAXILLARY MIDLINE DIASTEMA AMONG SAUDI SCHOOLCHILDREN IN RIYADH: PREVALENCE AND SOME RELATED ETIOLOGICAL FACTORS.
}

\author{
SAHAR F. AIBARAKATI ${ }^{1}$ and YOUSEF H. AL-DLAIGAN ${ }^{2}$ \\ ABSTRACT: \\ The aim of this study is to investigate the maxillary midline \\ diastema in Saudi schoolchildren in Riyadh; particularly prevalence \\ and some likely related etiological factors with regard to gender \\ and age. The present epidemiologic study was undertaken in \\ intermediate schools of Riyadh City. A total of 1,825 Saudi \\ schoolchildren (1007 boys and 818 girls) aged 12 to 16 years were \\ randomly selected. Clinical examination was carried out in the \\ schools within the students' classrooms by two experienced \\ examiners using simple plain mouth mirror, small light source and \\ stainless steel ruler. Students with a history of orthodontic \\ treatment or prosthodontic restorations in the upper anterior teeth \\ and periodontal disease were not included in the sample. An \\ especially composed chart was used to record demographic data \\ and inter arch parameters. All data were analyzed using SPSS \\ program and simple descriptive statistics with regard to boys and \\ girls. Results revealed the prevalence of maxillary midline \\ diastema was 394 (22\%) out of 1825 students examined. A similar \\ figure, though slightly greater prevalence of maxillary midline \\ diastema in boys (22\%) than in girls (21\%). The highest prevalence \\ was observed in 13 years age group (7.7\%). The width of maxillary
}

1- Associate Professor, Division of Orthodontics Department of Pediatric Dentistry and Orthodontics College of Dentistry, King Saud University.

2- Associate Professor, Division of Pediatric Dentistry, Department of Pediatric Dentistry and Orthodontics College of Dentistry, King Saud University. 
Egyptian

Orthodontic Journal

midline diastema ranged between 1-2 millimeters demonstrated (79.2\%) of total sample, greater in boys (91\%) than girls (64.4\%), and (100\%) in 16 years age group. The maxillary midline diastema width of 3-4 millimeters occurred more in girls (35\%) than boys (9\%), and in 12 years age group (35.5\%) than other age groups with decrease up to 16 years of age. Among the observed etiological factors in 6oth sexes and different age groups, spacing in anterior region (35.5\%) was the most frequent etiological factor associated with maxillary midline diastema. Followed by increased ovejet (15.7\%), missing tooth (11\%), while the frequency of deep bite and anterior open bite was $6.3 \%$ and $5.8 \%$ respectively. It was concluded that maxillary midline diastema is a common occurrence in Saudi children associated with multifactorial etiology. Consideration of etiological factors and individual treatment planning are essential in the proper management of maxillary midline diastema.

Key Word: diastema, malocclousion, children, maxillary, midline.

\section{INTRODUCTION}

Maxillary midline diastema is a common clinical finding of esthetic concern to parents and patients. Diastema is defined as a space greater than $0.5 \mathrm{~mm}$ between the proximal surfaces of adjacent teeth. ${ }^{(16)}$ It occurs more frequently in the median plane of the maxillary arch, and is therefore called median or midline diastema. ${ }^{(25)}$

The incidence of diastemas varies with age and race. Campbell and Kindela (2006) studied the maxillary midline diastema; they found as high as $98 \%$ in six year olds and decline sharply with age to be $49 \%$ in eleven year olds and 7\% in12-18 year olds. ${ }^{(6)}$ In another study, the prevalence of maxillary midline diastema has been reported in 18-25 year old UK residents of different population samples as 3.4\% in Caucasoids, $5.5 \%$ in Negroids and $1.7 \%$ in Mongoloids. ${ }^{(17)}$ While the incidence of $1.6 \%$ was found in South India. ${ }^{(20)}$ It is also possible the prevalence of 
midline diastema is related to sex. ${ }^{(18)}$ It had been reported the prevalence of midline diastema at age 14 years was higher in boys than in girls of the same race; $26 \%$ in black boys, $19 \%$ in black girls, $17 \%$ in white boys and $12 \%$ in white girls. ${ }^{(22)}$. In a study conducted in united state concerning the size of diastema of 5970 Panorex radiographs, McVay and Latta (1984) found that $22.33 \%$ had diastemas greater than 0.5 millimeters. ${ }^{(18)}$

No definite etiology for midline diastema has been identified. ${ }^{(20)}$ Gkantidis et al (2008) pointed out, most literature references to date promote that maxillary midline diastema is of multifactorial etiology. ${ }^{(14)}$ These factors varied and included environmental ${ }^{(15,19,20,21)}$ and hereditary factors. ${ }^{(13,20,23,24)}$ An accurate diagnosis and determination of contributing factors are necessary before the initiation of treatment. In a study of the causes of maxillary midline diastema, Oesterle and Shellhart (1999) reported the followings; midline diastema in children as a part of normal growth and development which spontaneously closes as canines come into occlusion resulting in a more favorable position of incisor roots. In adults, tooth size discrepancies and deep bite were the most common factors in the development of diastema. Overjet, generalized spacing and frenums were less frequent but important contributing factors. ${ }^{(21)}$ Other reported causative factors in literature involved; pathologic teeth migration due to periodontal disease, ${ }^{(10)}$ congenitally missing lateral incisors, ${ }^{(14,15)}$ supernumerary teeth at the midline, ${ }^{(14)}$ unusually small teeth, ${ }^{(14,15)}$ and combination of imperfect fusion and congenitally missing lateral incisors. ${ }^{(14)}$ Recently, Gass et al (2003) suggested that the midline diastema is probably inherited by an autosomal dominant mode of in heritance. $^{(13)}$

In a cross sectional study of a selective sample consisted of 641 models in Saudi patients seeking orthodontic treatment at king Saud University, Zahrani (1992) found the of maxillary midline diastema prevalent of $31.4 \%$ and there was significant relationship between the diastema and observed etiological factors. ${ }^{(28)}$ The scarce of local epidemiologic studies published on the frequency and etiology of midline diastema per se in Saudi Arabia trigger further studies to be conducted to understand the extent of the problem in this society in order to determine 
the optimal treatment. Therefore, the aim of the present epidemiologic study is to investigate the maxillary midline diastema; particularly prevalence and some likely related etiological factors with regard to gender and age, among the schoolchildren in Riyadh city, Saudi Arabia.

\section{SUBJECTS AND METHODS}

The present epidemiologic study was undertaken on twenty governmental schools (10 for boys and 10 for girls) were randomly selected from the list of Intermediate schools of Riyadh City utilizing the random number table from the strata composite of different areas of Riyadh City ( 4 schools from north, 4 schools from south, 4 schools from east, 4 schools from west and 4 schools from middle center of Riyadh).

A total of 1,825 Saudi students (1007 boys and 818 girls) aged 12 to 16 years with a mean age 14 years were randomly selected and examined. Ethical approval was obtained from the Research Centre at College of Dentistry (CDRC), Riyadh, Saudi Arabia and all the students were informed about their rights to participate in the study.

Clinical examination was carried out in the schools within the students' classrooms by two experienced examiners using simple plain mouth mirror, small light source and stainless steel ruler. Students with a history of orthodontic treatment or prosthodontic restorations in the upper anterior teeth and periodontal disease were not included in the sample. An especially composed chart was used to record demographic data included names, age, sex, medical history; dental history, any history of orthodontic treatment and inter arch parameters. ${ }^{(5,27)}$ Maxillary midline diastema was scored for the presence of spacing between the proximal surfaces of maxillary central incisors.

The widths of diastema were grouped and measured as follows:

1. A diastema of 1 to $2 \mathrm{~mm}$

2. A diastema of 3 to $4 \mathrm{~mm}$

3. A diastema of more than $6 \mathrm{~mm}$ 
Egyptian

Orthodontic Journal

The following etiological factors were recorded in relation to the midline diastema in the maxillary arch:

1. Deepbite $>3 \mathrm{~mm}$.

2. Anterior open bite $\geq 1 \mathrm{~mm}$.

3. Increased Over jet $>3 \mathrm{~mm}$.

4. Spacing of anterior region (Inter dental spaces judged subjectively and scored as larger than $0.5 \mathrm{~mm}$ in the maxillary anterior segment).

5. Missing tooth.

Before commencing data collection, the examiners participated in a methodology training session to review the clinical examination procedures and chart. A pilot study was conducted on 25 students. A set of calibrations was performed by the two examiners under identical conditions to the clinical examination method that followed. The result of the training session was compared and thoroughly discussed and necessarily final modifications to the chart were made accordingly.

In order to ensure the consistency of clinical examination, two calibrations were performed to assess intra and inter-examiner reliability using weighted Kappa coefficient. The intra-examiner reliability was tested on a group of 21 girls and 20 boys aged $12-16$ years old. All the boys and girls were examined by the same examiner on two separate occasions, within one week interval from the date of the first examination. The charts of the first examination were not available with the examiner at the second examination. The inter-examiner reliability was tested on another group of 20 children at King Saud University, Dental School. All the children were examined twice by the two examiners. The results of intra- examiner reliability on examined 20 boys and 21 girls showed $97 \%$ and 93\% agreement and weighted Kappa coefficient was found 0.87 and 0.81 respectively. The inter- examination reliability disclosed 93\% agreement and weight Kappa value was 0.83 . These figures indicate high level of agreement. ${ }^{(9)}$ 
The data were recorded by a trained assistant. All data were analyzed using SPSS program (version 16 SPSS Inc., Chicago, IL, USA). Simple descriptive statistics (percentage and frequency) of maxillary midline diastema and related factors with regard to gender and age groups were reported.

\section{RESULTS}

The Prevalence of maxillary midline diastema was $(22 \%)$. Out of 1825 students examined, 394 were found to have maxillary midline diastema. There is a similar figure though slightly greater prevalence of maxillary midline diastema in boys $220(22 \%)$ than in girls $174(21 \%)$ (Figure.1).

Boys $\square$ Girls

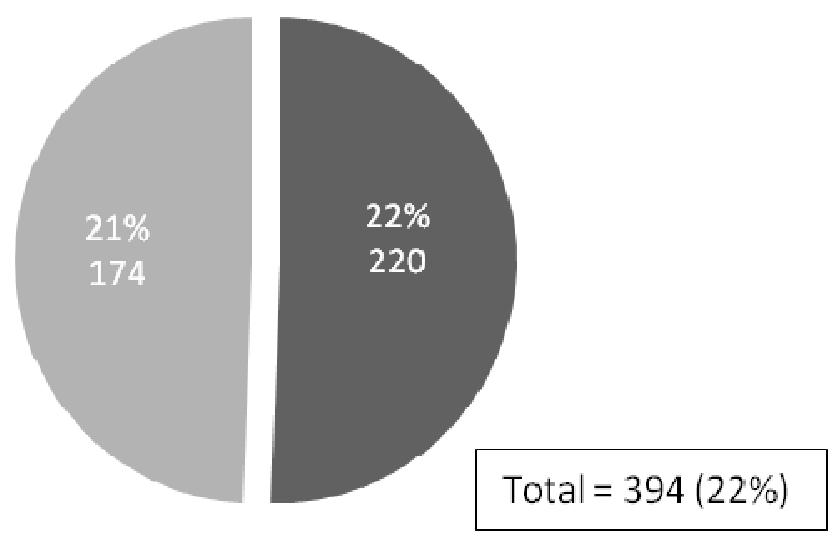

Figure 1. Prevalence of Maxillary Midline Diastema in 1825 schoolchildren in relation to gender.

The highest prevalence of maxillary midline diastema was observed in 13 years age group $141(7.7 \%)$ and the least prevalent in 16 years age group 30(1.6\%) (Figure.2). 
Egyptian

Orthodontic Journal

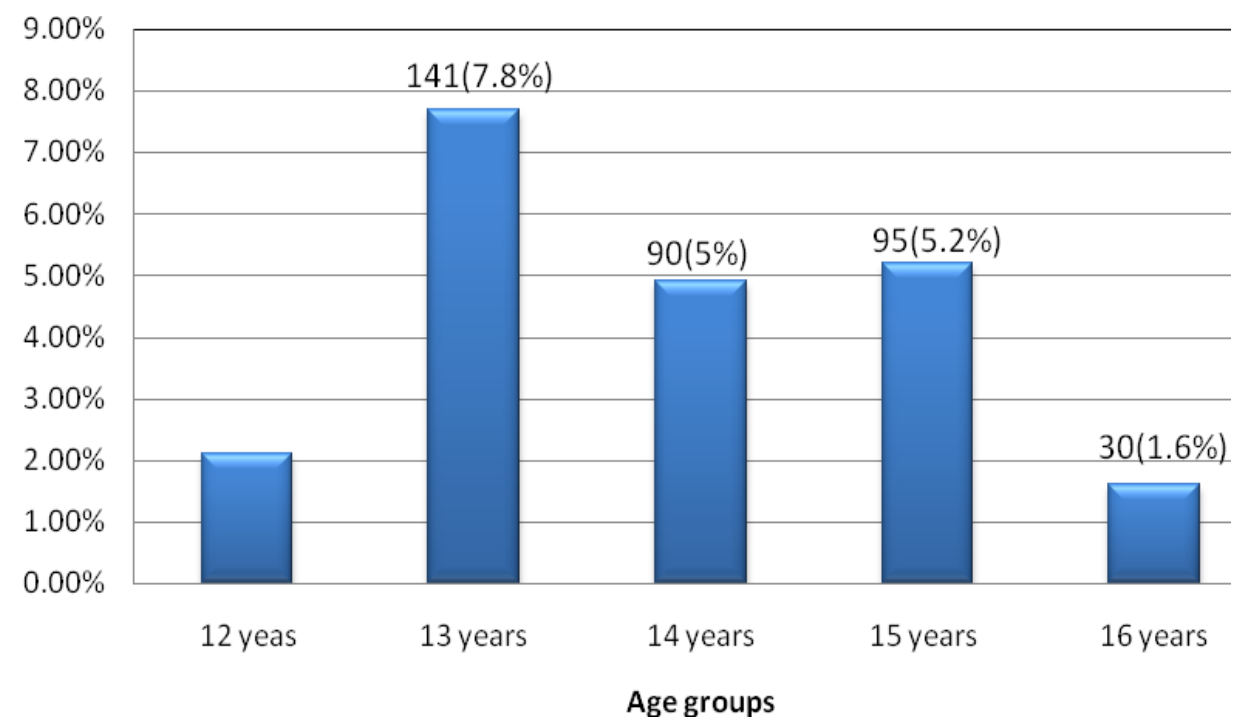

Figure 2. Prevalence of Maxillary Midline Diastema in 1825 schoolchildren in relation to age groups.

In both sexes and different age groups (Table 1and 2), the width of maxillary midline diastema ranged between 1-2 millimeters demonstrated the highest frequency $(79.2 \%)$ compared to other widths' frequencies ( $20 \%$ and $0.2 \%$ respectively). It also showed to be greater in boys $(91 \%)$ than girls (64.4\%) (Table 1), and encountered more frequently in 16 years age group $(100 \%)$ than other age groups (Table 2). In contrast, the maxillary midline diastema width of 3-4 millimeters occured more predominantly in girls (35\%) than boys $(9 \%)$ (Table 1$)$, and in 12 years age group (35.5\%) than other age groups with decrease up to 16 years of age (Table 2). However, the analysis of data showed the width of diastema was unrelated to the sex.

Table 1: Width of Maxillary Midline Diastema in relation to gender.

\begin{tabular}{|c|c|c|c|c|c|c|}
\hline \multirow{2}{*}{$\begin{array}{c}\text { Width of Maxillary Midline } \\
\text { Diastema }\end{array}$} & \multicolumn{2}{|c|}{ Boys } & \multicolumn{2}{|c|}{ Girls } & \multicolumn{2}{|c|}{ Total } \\
\hline & No & $\%$ & No & $\%$ & No & $\%$ \\
\hline $1-2 \mathrm{~mm}$ & 200 & $91 \%$ & 112 & $64.4 \%$ & 312 & $79.2 \%$ \\
\hline $3-4 \mathrm{~mm}$ & 20 & $9 \%$ & 61 & $35 \%$ & 81 & $20.6 \%$ \\
\hline More than $4 \mathrm{~mm}$ & - & - & 1 & $0.6 \%$ & 1 & $0.2 \%$ \\
\hline Total & 220 & $100 \%$ & 174 & $100 \%$ & 394 & $100 \%$ \\
\hline
\end{tabular}

Volume 40-December 2011 
Table 2. Width of Maxillary Midline Diastema in relation to age groups.

\begin{tabular}{|c|c|c|c|c|c|c|c|c|c|c|c|c|}
\hline \multirow{3}{*}{$\begin{array}{c}\text { Width of } \\
\text { Maxillary Midline } \\
\text { Diastema }\end{array}$} & \multicolumn{10}{|c|}{ Age groups } & \multirow{2}{*}{\multicolumn{2}{|c|}{ Total }} \\
\hline & \multicolumn{2}{|c|}{12 years } & \multicolumn{2}{|c|}{13 years } & \multicolumn{2}{|c|}{14 years } & \multicolumn{2}{|c|}{15 years } & \multicolumn{2}{|c|}{16 years } & & \\
\hline & No & $\%$ & & & & $\%$ & & $\%$ & & $\%$ & & $\%$ \\
\hline $1-2 \mathrm{~mm}$ & 17 & $44.7 \%$ & 108 & $76.6 \%$ & 69 & $76.7 \%$ & 88 & $92.6 \%$ & 30 & $100 \%$ & 312 & $79.2 \%$ \\
\hline $3-4 \mathrm{~mm}$ & 21 & $55.3 \%$ & 33 & $23.4 \%$ & 20 & $22.2 \%$ & 7 & $7.4 \%$ & - & - & 81 & $20.6 \%$ \\
\hline More than $4 \mathrm{~mm}$ & - & - & - & - & 1 & $1.1 \%$ & - & - & - & - & & $0.2 \%$ \\
\hline Total & 38 & $100 \%$ & 141 & $100 \%$ & 90 & $100 \%$ & 95 & $100 \%$ & 30 & $100 \%$ & 394 & $100 \%$ \\
\hline
\end{tabular}

Among the observed etiological factors (Table 3 and 4), the majority of the students in both sexes and different age groups exhibited spacing in anterior region $(35.5 \%)$ as the most frequent etiological factor associated with maxillary midline diastema. Followed by increased ovejet $(15.7 \%)$, missing tooth (11\%), while the frequency of deep bite and anterior open bite was $6.3 \%$ and $5.8 \%$ respectively.

Table 3. Etiological Factors of Maxillary Midline Diastema in relation to gender.

\begin{tabular}{|l|cc|cc|cc|}
\hline \multirow{2}{*}{ Factors } & \multicolumn{2}{c|}{$\begin{array}{c}\text { Boys } \\
\text { (N=220) }\end{array}$} & \multicolumn{2}{c|}{$\begin{array}{c}\text { Girls } \\
\text { (N=174) }\end{array}$} & \multicolumn{2}{c|}{$\begin{array}{c}\text { Total } \\
\text { (N=394) } \\
\text { No }\end{array}$} \\
\hline $\begin{array}{l}\text { Deepbite } \\
>3 \text { mm. }\end{array}$ & 15 & $6.8 \%$ & 10 & $5.7 \%$ & 25 & $6.3 \%$ \\
\hline $\begin{array}{l}\text { Anterior open bite } \\
\geq 1 \mathrm{~mm} .\end{array}$ & 18 & $8.2 \%$ & 5 & $2.9 \%$ & 23 & $5.8 \%$ \\
\hline $\begin{array}{l}\text { Increased Overjet } \\
>3 \text { mm. }\end{array}$ & 48 & $21.8 \%$ & 14 & $8 \%$ & 62 & $15.7 \%$ \\
\hline Spacing in anterior region & 114 & $51.8 \%$ & 26 & $15 \%$ & 140 & $35.5 \%$ \\
\hline Missing tooth & 37 & $16.8 \%$ & 6 & $3.4 \%$ & 43 & $11 \%$ \\
\hline
\end{tabular}

Table 4. Etiological Factors of Maxillary Midline Diastema in relation to age groups.

\begin{tabular}{|c|c|c|c|c|c|c|c|c|c|c|c|c|}
\hline \multirow{3}{*}{ Factors } & \multicolumn{10}{|c|}{ Age groups } & \multirow{2}{*}{\multicolumn{2}{|c|}{$\begin{array}{c}\text { Total } \\
(\mathbf{N}=394)\end{array}$}} \\
\hline & \multicolumn{2}{|c|}{$\begin{array}{c}12 \text { years } \\
(\mathrm{N}=38)\end{array}$} & \multicolumn{2}{|c|}{$\begin{array}{l}13 \text { years } \\
(\mathrm{N}=141)\end{array}$} & \multicolumn{2}{|c|}{$\begin{array}{c}14 \text { years } \\
(\mathrm{N}=90)\end{array}$} & \multicolumn{2}{|c|}{$\begin{array}{l}15 \text { years } \\
(\mathrm{N}=95)\end{array}$} & \multicolumn{2}{|c|}{$\begin{array}{l}16 \text { years } \\
(\mathrm{N}=30)\end{array}$} & & \\
\hline & No & & No & $\%$ & No & $\%$ & No & $\%$ & No & $\%$ & No & $\%$ \\
\hline $\begin{array}{l}\text { Deepbite } \\
>3 \mathrm{~mm}\end{array}$ & 4 & $10.5 \%$ & 8 & $5.7 \%$ & 9 & $10 \%$ & 2 & $2.1 \%$ & 2 & $6.7 \%$ & 25 & $6.3 \%$ \\
\hline $\begin{array}{l}\text { Anterior open bite } \\
\geq 1 \mathrm{~mm} \text {. }\end{array}$ & 2 & $5.2 \%$ & 2 & $1.4 \%$ & 12 & $13.3 \%$ & 5 & $5.3 \%$ & 2 & $6.7 \%$ & 23 & $5.8 \%$ \\
\hline $\begin{array}{l}\text { Increased Overjet } \\
>3 \mathrm{~mm} \text {. }\end{array}$ & 3 & $7.9 \%$ & 15 & $16.6 \%$ & 21 & $23.3 \%$ & 18 & $19 \%$ & 5 & $16.7 \%$ & 62 & $15.7 \%$ \\
\hline $\begin{array}{l}\text { Spacing in anterior } \\
\text { region }\end{array}$ & 5 & $13.2 \%$ & 50 & $35.5 \%$ & 44 & $48.9 \%$ & 30 & $31.6 \%$ & 11 & $36.7 \%$ & 140 & $35.5 \%$ \\
\hline Missing tooth & 2 & $5.2 \%$ & 9 & $6.4 \%$ & 17 & $18.9 \%$ & 13 & $13.7 \%$ & 2 & $6.7 \%$ & 43 & $11 \%$ \\
\hline
\end{tabular}


Egyptian

Orthodontic Journal

As presented in Table 3, all observed etiological factors appeared to be more significant in boys than in girls. The existence of deep bite in boys and anterior open bite in girls were the least significant causative factors $(6.8 \%$ and $2.9 \%$ respectively). Table 4 displayed spacing in anterior region as the most common etiological factor in 14 years age group $(48.9 \%)$, also most common in all other age groups. Increased overjet $(23.3 \%)$, followed by missing teeth $(18.9 \%)$ were observed to be the next significant contributed factors in 14 years age group and other age groups except 12 years age group showed that the deep bite was the second ranked etiological factor $(10.5 \%)$. On other hand, deep bite was the least frequent etiological factor in all age groups. While in 12 years age group, anterior open bite and missing teeth were observed to be the least common contributing factors $(5.2 \%)$.

\section{DISCUSSION}

The current research was based on a large sample, that is representative of Saudi schoolchildren to a great extent, aged 12- 16 years in Riyadh city, Saudi Arabia. There were main positive values of this study; the random subject selection was according to stratified cluster sample method, ${ }^{(12)}$ clinical examination based on a standardized and repeatable methodology. ${ }^{(5.27)}$ The high intra and inter-examiner reliability which resulted in consistency of calibration and reduce the risk of methodological misjudgments. ${ }^{(26)}$ The exclusion of children who had a history of orthodontic treatment or prosthodontic restorations in the upper anterior teeth and periodontal disease; as maxillary midline diastema is no longer possible to be determined accordingly. ${ }^{(18)}$ However, Thilander et al (2001) noted that in studies concerning the prevalence of malocclusion or occlusal problems, the material should be obtained from a well-defined population and be large enough and cover non-orthodontically treated children. ${ }^{(26)}$ The present sample seems to satisfy those requirements.

The sample was comprised of Saudi students aged 12-16 years. Students under 12 years were excluded to avoid cases of midline diastema due to the normal stages of development, ${ }^{(20)}$ and students above 16 years were excluded to avoid the start of periodontal disease which 
may contribute to diastema formation. Despite homogeneity of the ethnicity and age of the sample provided positive value to the study, there is also a limitation as the selected age did not provide information on the rest of the Saudi population. This is in agreement with the finding reported by Ciuffolo et al (2005). ${ }^{(11)}$

In the present study, the prevalence of maxillary midline diastema $(22 \%)$ was similar to the finding $(22.33 \%)$ recorded by McVay and Latta (1984) in his study in United State. ${ }^{(18)}$ On other hand, it displayed a remarkable higher figure as compared to Caucasoids (3.4\%), Negroids $(5.5 \%)$, Mongoloids $(1.7 \%)^{(17)}$ and $1.6 \%$ of South India. ${ }^{(20)}$ Other epidemiological studies of malocclusion conducted in Middle Eastern countries showed lower prevalence figures of maxillary midline diastema than this study, in Kuwaitis $(0.8 \%)^{(4)}$ and Jordanians $(6.9 \%)^{(1)}$. In comparison with some publications carried out in Saudi Arabia, the prevalence of maxillary midline diastema was unlike AL-Emran et al (1990) study who reported very low figure (3.6\%) in 14 years old male schoolchildren. ${ }^{(3)}$ It was also in contradiction with Zahrani (1992) finding who observed higher frequency $(31.4 \%)$ in Saudi patients seeking orthodontic treatment. ${ }^{(28)}$

The most likely explanation of the existing variation in the frequency of maxillary midline diastema in different epidemiological studies seems to be due to ethnicity, registration methods, sample composition and genetic predisposition. ${ }^{(26)}$ Therefore, the influence of the above factors must be taken into account when comparing findings from different surveys. ${ }^{(11)}$ Another explanation could be due to human evolutionary development and the effect of increased out-breeding. ${ }^{(4)}$ While the highly reporting frequency in Zahrani (1992) study could be attributed to the fact that the sample was patients seeking orthodontic treatment and had malocclusion. ${ }^{(28)}$

The results of the current study revealed no marked sex differences though slightly greater prevalence of midline diastema was observed in boys than girls. This corresponded well with the observation of Celikoglu et al (2010) who observed almost equally distributed with slightly higher prevalence midline diastema in males than females. ${ }^{(7)}$ A similar finding was noticed by Nainar and Gnanasundaram (1989) as well as Richardson 
(1973) who found greater incidence in males than females. $(20,22)$ Richardson (1973) explained this phenomenon by reasoning that girls mature more quickly than boys. ${ }^{(22)}$ In contrast, Zahrani (1992) noticed higher frequency in females than males. ${ }^{(28)}$ The finding could be related to the sample was patients seeking orthodontic treatment. It is common experience that the girls seek the orthodontic treatment due to the greater level of esthetic concern than the boys. ${ }^{(2)}$

Concerning the prevalence midline diastema in age groups, it was clearly shown that beginning at 13 years old of age was more likely to have the highest occurrence followed by a sharp decrease until 16 years of age. The result was in agreement with Campbell and Kindela (2006) who observed continuous decrease in12-18 year olds. ${ }^{(6)}$

In the present study, the obvious highest frequency $(79.2 \%)$ of $1-2$ $\mathrm{mm}$ width of maxillary midline diastema within the whole sample was in agreement with Zahrani (1992) observation. ${ }^{(28)}$ Despite he displayed slightly less figure $(73 \%)$ than that reported in this study. The results also suggested that 1-2 mm width of maxillary midline diastema was more predominant feature in boys than girls. Similar result was reported by Zahrani (1992) ${ }^{(28)}$ On other hand, the maxillary midline diastema width of 3-4 mm was more common in girls than boys. This was in accordance with Zahrani (1992) observation, ${ }^{(28)}$ and in contrary to Thilander et al (2001) finding. ${ }^{(26)}$ Another interesting observation, 3-4 mm width of diastema was the most common in 12 years age. It might be due to incomplete eruption of permanent canines and the consequence as observed in the study was persistent space between maxillary central incisors. ${ }^{(14)}$

In most subjects, no single etiological factor was attributable, hence only frequencies had been noted. Spacing in anterior region appeared to be the most significant factor associated with maxillary midline diastema. In most instances, the maxillary anterior segment of dental arch exhibited more spacing than any other segment which was always accompanied by a midline diastema. A good agreement was found between the present result and those reported by Steigman and Weissberg (1985), ${ }^{(25)}$ Nainar and Gnanasundaram (1989), ${ }^{(20)}$ as well as Zahrani (1992). ${ }^{(28)}$ However, it worth mentioning that the initial width of the diastema and additional spaces between the maxillary anterior teeth are the most predictive factors of relapse following orthodontic treatment. ${ }^{(24)}$ 
The significant occurrence of increased overjet and deep bite (in 12 years) as the second most common cause of maxillary midline diastema could be attributed to fact that various occlusal problems often are associated with the diastema. These problems include overjet and deep bite. ${ }^{(15)}$ This is in contrast to Oesterle and Shellhart (1999) study that reported overjet and generalized spacing was less frequent contributing factors, while the deep bite was the most found significantly associated with maxillaly midline diastema. ${ }^{(21)}$

Missing teeth was another common cause creating spacing distributed along the whole dental arch and in particular in anterior segment due to failure of spontaneous closure especially after tooth extraction. The dilemma for clinicians is whether to close, open or redistribute space. Closing space by orthodontics eliminates the need for prosthetic rehabilitation but it might compromise aesthetics and function. The prognosis for closing space and substituting missing maxillary laterals with canines depends on factors such as overjet, lip support, crown colour, shape and root position. If these are unfavorable, opening space for prosthetic replacement is then preferred. ${ }^{(8)}$

The epidemiological data on the prevalence of maxillary midline diastema is important determent to provide accurate estimates in planning appropriate levels of orthodontic services and other treatment need in Saudi population. Further studies are required to involve wider age groups, more etiological factors and different regions in Saudi Arabia.

\section{CONCLUSION}

- Maxillary midline diastema is a common problem with a prevalence of $22 \%$ in Saudi schoolchildren sample.

- The differences in the width of maxillary midline diastema were significant with regard to the sex and age.

- The width of maxillary midline diastema decreased with age.

- Spacing in anterior region was the most significant factor associated with maxillary midline diastema followed by overjet.

- Addressing the maxillary midline diastema, along with consideration of etiological factors are essential in the proper management and avoiding relapse. 
Egyptian

Orthodontic Journal

\section{ACKNOWLEDGEMENT}

The authors would like to thank all the children and their schools for their cooperation in this study as well as the Research Center at KSU, for support and for the assistance and advice for this study.

\section{REFERENCES}

1. Abu Alhaija ES, Al-Khateeb SN, Al-Nimri KS. Prevalence of malocclusion in 13 - 15 year-old North Jordanian schoolchildren. Community Dental Health. 22: 266 - 271, 2005.

2. ALBarakati, SF. The characteristic features of malocclusion among Saudi females seeking orthodontic treatment. Egyp Dent J. 53: 1587 - 95, 2007.

3. Al-Emran S, Wisth PJ, Bøe OE. Prevalence of malocclusion and need for orthodontic treatment in Saudi Arabia. Community Dent Oral Epidemiol. 18: 253-255, 1990.

4. Behbehani F, Årtun J, Al-Jame B, Kerosuo H. Prevalence and severity of malocclusion in adolescent Kuwaitis . Medical Principles and Practice 14: 390 - 395, 2005.

5. Burden DJ, Mitropoulous CM, Shaw WC. Residual orthodontic treatment need in a sample of 15- and 16-year-olds. Br Dent J. 176:220-224, 1994.

6. Campbell A, Kindela J. Maxillary midline diastema a case report involving a combined orthodontic / maxillofacial approach. J Orthod. 33: 22-27, 2006.

7. Celikoglu M, Akpinar S, Yavuz I. The pattern of malocclusion in a sample of orthodontic patients from Turkey. Med Oral Patol Oral Cir Bucal. 15: 791-6, 2010.

8. Chay SH, Ho KK. Spaced dentition- open, close or redistribute? Ann R Australas Coll Dent Surg. 15:83- 6. 2000.

9. Cicchetti Dv. Assessing inter-rated reliability for rating scales; resolving some basic issues. British J of Psychology. 129: 452-456, 1976.

10. Cirelli JA, Cirelli CC, Holzhausen M, Martins LP, Brandao CH. Combined periodontal, orthodontic, and restorative treatment of pathologic migration of anterior teeth: a case report. Int $\mathrm{J}$ Periodontics Restorative Dent. 26: 501-506, 2006. 
11. Ciuffolo $\mathrm{F}$ et al. Prevalence and distribution by gender of occlusal characteristics in a sample of Italian secondary school students: a cross sectional study. Europ J Orthod. 27: 601 -606, 2005

12. Cochran WG: Sampling Techniques. New York, Wiley, 1977.

13. Gass JR, Valiathan M, Tiwari HK, Hans MG, Elston RC. Familial correlations and heritability of maxillary midline diastema. Am $\mathrm{J}$ Orthod Dentofac Orthop. 123: 35-39, 2003.

14. Gkantidis N, Kolokitha OE, Topouzelis N. Management of maxillary midline diastema with emphasis on etiology. J Clin Pediatr Dent. 32:265-272, 2008.

15. Huang WJ, Creath CJ. The midline diastema. A review of its etiology and treatment. Pediatr Dent.17: 171-179, 1995.

16. Keene HJ. Distribution of diastemas in the dentition of man. Am J Phys Anthropol. 21: 437-41, 1963.

17. Lavelle CLB. The distribution of diastemas in different human ponpulation samples. Scand J Dent Res. 78: 530-534, 1970.

18. McVay TJ, Latta GH Jr. Incidence of the maxillary midline diastemas in adults. J Prosthet Dent. 52: 809-811, 1984.

19. Mittal M, Murray AM, Sandler PJ. Maxillary labial fraenectomy: indications and technique. Dent Update. 38:159-162, 2011.

20. Nainar SM, Gnanasundaram N. Incidence and etiology of midline diastema in a population in south India (Madras). Angle Orthod. 59: 277-2 82, 1989.

21. Oesterle LJ, Shellhart WC. Maxillary midline diastemas: a look at the causes. J Am Dent Assoc. 30: 85-94, 1999.

22. Richardson ER, Malhotra SK, Henry M, Little RG, Coleman HT. Biracial study of the maxillary midline diastema. Angle Orthod. 43:438-443, 1973.

23. Sabri R, Aboujaoude N. Agenesis of the maxillary lateral incisors: orthodontic and implant approach. Orthod Fr. 79:283-93, 2008. 
24. Shashua D, Artun J. Relapse after orthodontic correction of maxillary median diastema: a follow-up evaluation of consecutive cases. Angle Orthod. 69: 257-263, 1999.

25. Steigman S, Weissberg Y. Spaced dentition. An epidemiologic study. Angle Orthod. 55: 167-176, 1985.

26. Thilander B, Pena L, Infante C, Parada SS, De Mayorga C. Prevalence of malocclusion and orthodontic treatment need in children and adolescents in Bogota, Colombia. An epidemiologic study related to different stages of dental development. Eur J Orthod. 23: 153-167, 2001.

27. Wheeler TT, McGorray SP, Yurkiewicz L, Keeling SD, King GJ. Orthodontic treatment demand and need in third and fourth grade schoolchildren. Am J Orthod Dento Fac Orthop. 106:22-33,1994.

28. Zahrani AA. Prevalence and aetiology of maxillary median diastema among a Saudi population seeking orthodontic treatment. Alexandria Dent J. 12: 25-35, 1992. 